\title{
Pengaruh Tingkat Inflasi, Modal Kerja, Dan Loan To Deposit Ratio Terhadap Profitabilitas Pada Perusahaan Perbankan Yang Terdaftar Di Bei Periode 2015 - 2019
}

\author{
Novien Rialdy ${ }^{1}$ \\ Universitas Muhammadiyah Sumatera Utara ${ }^{1}$ \\ Email: novienrialdy@umsu.ac.id
}

\begin{abstract}
Abstrak: Tujuan diadakannya penelitian ini adalah untuk menguji dan menganalisis pengaruh tingkat inflasi, modal kerja dan Loan to Depsoit Ratio terhadap profitabilitas pada perusahaan perbankan yang terdaftar di BEI periode 2015-2019. Variabel independen dalam penelitian ini adalah tingkat inflasi, modal kerja dan LDR sedangkan variabel dependen adalah profitabilitas. Profitabilitas yang digunakan dalam penelitian ini adalah Return On Assets. Teori yang digunakan dalam penelitian tersebut adalah yang berhubungan dengan tingkat inflasi, modal kerja, LDR dan profitabilitas. Metode yang digunakan dalam penelitian ini adalah pendekatan kuantitatif, jenis penelitian ini adalah deskriptif, sifat penelitian adalah bersifat eksplanasi, jenis data sekunder. Populasi yang digunakan dalam penelitian ini adalah perusahaan perbankan yang berjumlah 42 perusahaan, dengan menggunakan teknik purposive sampling didapat sampel sebanyak 24 perusahaan. Hasil penelitian ini menunjukkan secara simultan, tingkat inflasi, modal kerja LDR berpengaruh signifikan terhadap profitabilitas pada perusahaan perbankan di BEI periode 2015-2019. Hasil Uji Koefisien Determinasi diketahui sebesar 0,343 artinya dari variabel-variabel dependen profitabilitas yang dapat dijelaskan oleh variabel independen tingkat inflasi, modal kerja dan LDR sedangkan sisanya dijelaskan oleh variabel-variabel lain di luar dari variabel yang diteliti. Kesimpulan penelitian ini adalah secara parsial inflasi, modal kerja dan LDR berpengaruh terhadap profitabilitas pada perusahaan perbankan yang terdaftar di BEI periode 2015-2019.
\end{abstract}

Kata Kunci : Tingkat Inflasi, Modal Kerja, Loan to Deposit Ratio dan Profitabilitas

Bank merupakan salah satu lembaga keuangan yang berfungsi sebagai perantara antara pihak atau masyarakat yang memilki dana lebih dengan pihak lain yang membutuhkan dana (Margaretha, 2007). Oleh karena itu bank bertugas untuk menyalurkan dana yang dihimpun untuk diinvestasikan dalam bentuk kredit atau pembiayaan. Setiap perusahaan ingin memperoleh keuntungan (Wijaya, 2009). Untuk mencapai tujuan tersebut, perusahaan harus memperhatikan faktor eksternal dan internal profitabilitas perusahaan (Fitriani Saragih, 2017). Faktor internal merupakan faktor mikro atau spesifik yang menentukan profitabilitas sedangkan faktor eksternal merupakan faktor yang tidak memiliki hubungan langsung dengan manajemen tetapi memberikan dampak terhadap lembaga keuangan (Rahardja, 2008).

Salah satu faktor eksternal yang tidak dapat dikontrol yaitu inflasi (Murhadi, 2013). Naik turunnya inflasi akan memberikan pengaruh besar bagi keberadaan bisnis atau perusahaan baik perusahaan jasa, dagang maupun manufaktur (Putong, 2008). Salah satu jenis perusahaan yang tidak luput dari pengaruh inflasi yaitu perusahaan perbankan (Jumingan, 2014). Sehingga pihak manajemen dalam perusahaan khususnya 
perbankan melakukan berbagai cara atau strategi dalam hal masalah inflasi (Sembiring, 2019).

Dalam menjalankan usaha, setiap perusahaan memerlukan modal kerja agar dapat menjalankan aktivitas perusahaan (Nainggolan, 2016). Manajemen harus dapat mengelola modal kerja perusahaan yang dikelolanya secara maksimal agar memberikan manfaat bagi perusahaan dalam mencapai tujuan utama perusahaan (Harmono, 2015). Besarnya modal kerja yang ada pada perusahaan mampu memberikan peluang yang besar bagi perusahaan dalam meningkatkan kemajuan perusahaan (Surya Sanjaya, 2019).

Salah satu tugas bank yaitu menghimpun dana dan menyalurkan dana sebanyak-banyaknya kepada pihak yang membutuhkan dana untuk mengembangkan usahanya dalam bentuk kredit (Rajaharputra, 2011). Faktor yang menjadi alasan masyarakat atau pihak-pihak yang menyimpan atau menginvestasikan dananya kepada perusahan perbankan yaitu seberapa baik tingkat likuiditas yang dipunyai bank tersebut (Alpi, 2018). Salah satu rasio likuiditas perbankan yaitu loan to deposit rasio (LDR), yaitu merupakan rasio yang digunakan untuk mengukur seberapa besar komposisi jumlah kredit yang diberikan atau disalurkan dengan jumlah dana masyarakat dan modal sendiri (Harahap, 2008). Semakin besar kredit yang diberikan maka semakin banyak kesempatan memperoleh keuntungan lebih besar (Pandia, 2012).

\section{Identifikasi Masalah}

Berdasarkan uraian dalam latar belakang masalah, maka identifikasi masalah sebagai berikut :

1. Peningkatan inflasi tidak diikuti dengan peningkatan profitabilitas pada perusahaan perbankan yang terdaftar di BEI Periode 20152019.

2. Peningkatan modal kerja tidak diikuti dengan peningkatan profitabilitas pada perusahaan perbankan yang terdaftar di BEl Periode 2015-2019.

3. Peningkatan LDR tidak diikuti dengan peningkatan profitabilitas pada perusahaan perbankan yang terdaftar di BEI Periode 2015-2019.

4. Peningkatan inflasi, modal kerja dan LDR tidak diikuti dengan peningkatan profitabilitas pada perusahaan perbankan yang terdaftar di BEI Periode 2015-2019.

\section{Teori Tentang Inflasi}

Menurut (Murhadi, Analisis Laporan Keuangan, 2013, hal. 72), inflasi merupakan kondisi dimana jumlah barang yang beredar lebih sedikit dari jumlah permintaan sehingga akan mengakibatkan terjadinya kenaikan harga yang meluas dalam sistem perekonomian secara keseluruhan (Husnan, 2015).

Teori Tentang Modal Kerja 
Menurut (Fahmi, 2012, hal. 100), modal kerja adalah investasi sebuah perusahaan pada aktiva-aktiva jangka pendek kas, sekuritas, persediaan dan piutang (Sudana, 2011).

Teori Tentang LDR

Menurut (Kasmir, 2012, hal. 225), loan to deposit rasio merupakan rasio yang digunakan untuk mengukur komposisi jumlah kredit yang diberikan dengan jumlah dana masyarakat dan modal sendiri yang digunakan. Besarnya loan to deposit ratio menurut peraturan pemerintah maksimum adalah 100\% (Rosyidi, 2012) .

Teori Tentang Profitabilitas

Menurut (Hery, 2015, hal. 226), rasio profitabilitas merupakan rasio yang digunakan untuk mengukur kemampuan perusahaan dalam menghasilkan laba dari aktivitas normal bisnisnya.

Teori Pengaruh Tingkat Inflasi Terhadap Profitabilitas

Menurut (Fahmi, 2012, hal. 80), inflasi dapat meningkatkan pendapatan dan biaya bagi perusahaan, yaitu jika peningkatan biaya produksi lebih tinggi dari peningkatan harga yang dapat dinikmati oleh perusahaan maka profitabilitas perusahaan akan turun (Fitriani Saragih, 2017).

Teori Pengaruh Modal Kerja Terhadap Profitabilitas

Menurut (Fahmi, 2013, hal. 103), menyatakan bahwa semakin besar suatu perusahaan maka kebutuhan dana untuk menunjang modal kerja juga akan semakin tinggi, dan itu diikuti juga dengan harus semakin tinggi perputaran yang bisa diberikan agar tertutupinya biaya modal kerja yang telah dikeluarkan maka artinya perusahaan akan memperoleh keuntungan (profit), dan begitu pula sebaliknya (Rialdy, 2019).

Teori Pengaruh LDR Terhadap Profitabilitas

Menurut (Hariyani, 2010, hal. 57), menyatakan besarnya LDR akan berpengaruh terhadap laba melalui penciptaan kredit. LDR yang tinggi mengindikasikan adanya penanaman dana dari pihak ketiga yang besar ke dalam bentuk kredit. Kredit yang besar akan meningkatkan laba (Subramanyam, 2013).

\section{METODE PENELITIAN}

Pendekatan penelitian yang digunakan dalam penelitian ini adalah metode regresi linear berganda (Linear Regression Method) (Sujarweni, 2014). Jenis penelitian yang digunakan dalam penelitian ini adalah jenis deskriptif kuantitatif (Prasetyo, 2010). Sifat penelitian yang digunakan dalam penelitian ini adalah penelitian explanatory (Kuncoro, 2009).

Populasi yang digunakan dalam penelitian ini adalah seluruh perusahaan perbankan yang terdaftar di Bursa Efek Indonesia periode 2015-2019.

\section{HASIL PENELITIAN}

Hasil Uji Asumsi Klasik

Uji asumsi klasik merupakan suatu persyaratan statistik yang harus dipenuhi untuk melakukan analisis regresi linear, hal ini bertujuan untuk mengetahui apakah data yang diteliti telah memenuhi sebuah kelayakan 
dalam penelitian (Suryabrata, 2012). Hasil pengujian asumsi klasik yang digunakan dalam penelitian ini adalah :

Uji Normalitas

Uji normalitas bertujuan untuk mengetahui data yang digunakan dalam penelitian ini terdapat distribusi normal atau terjadi pelanggaran asumsi yang mengakibatkan data menjadi tidak valid.

Hasil Pengujian Normalitas Kolmogorov-Smirnov

Tabel 1 One-Sample Kolmogorov-Smirnov Test

Tabel 1 One-Sample Kolmogorov-Smirnov Test

\begin{tabular}{|c|c|c|}
\hline & & Unstandardized Residual \\
\hline $\begin{array}{l}\text { Normal Parameters } \\
\text { Na,b } \\
\text { Most Extreme Differences } \\
\text { Kolmogorov-Smirnov Z } \\
\text { Asymp. Sig. (2-tailed) }\end{array}$ & $\begin{array}{l}\text { Mean } \\
\text { Std. Deviation } \\
\text { Absolute } \\
\text { Positive } \\
\text { Negative }\end{array}$ & $\begin{array}{r}120 \\
0 \mathrm{E}-7 \\
3.61808846 \\
.082 \\
.082 \\
-.064 \\
.899 \\
.394\end{array}$ \\
\hline
\end{tabular}

a. Test distribution is Normal.

b. Calculated from data.

Berdasarkan tabel diatas menunjukkan nilai hasil uji Kolmogorov-Smirnov setelah transformasi terdistribusi normal dengan Asymp. Sig. (2-tailed) $>0,05$ yaitu sebesar 0,394, sehingga model memiliki residual yang terdistribusi normal.

Uji Multikolinearitas

Uji multikolinearitas bertujuan untuk menguji ada atau tidaknya korelasi antar variabel independen dalam model regresi. Dalam model penelitian ini uji multikolinearitas diukur melalui nilai variance inflation factor (VIF). Pengujian multikolinearitas dilakukan dengan melihat VIF dan nilai tolerance antar variabel independen.

Tabel 2 Hasil Uji Multikolinearitas

Coefficients $^{a}$

\begin{tabular}{|c|c|c|c|c|c|c|c|}
\hline \multirow[t]{2}{*}{ Model } & \multicolumn{2}{|c|}{$\begin{array}{l}\text { Unstandardized } \\
\text { Coefficients }\end{array}$} & \multirow{2}{*}{\begin{tabular}{|c|}
$\begin{array}{c}\text { Standardized } \\
\text { Coefficients }\end{array}$ \\
Beta \\
\end{tabular}} & \multirow[t]{2}{*}{$\mathrm{t}$} & \multirow[t]{2}{*}{ Sig. } & \multicolumn{2}{|c|}{$\begin{array}{l}\text { Collinearity } \\
\text { Statistics }\end{array}$} \\
\hline & B & Std. Error & & & & Tolerance & VIF \\
\hline (Constant) & 7.440 & 2.281 & & 3.262 & .001 & & \\
\hline SQRT_X1 & -.158 & .084 & -.141 & -1.886 & .062 & .983 & 1.017 \\
\hline SQRT_X2 & $\begin{array}{l}2.978 \mathrm{E}- \\
007\end{array}$ & .000 & .184 & 2.436 & .016 & .967 & 1.034 \\
\hline SQRT_X3 & .103 & .013 & .599 & 7.917 & .000 & .966 & 1.035 \\
\hline
\end{tabular}

a. Dependent Variable: SQRT_Y 
Berdasarkan uji multikolinearitas pada tabel diatas diketahui bahwa nilai tolerance value semua variabel independen yaitu inflasi sebagai $X 1$, modal kerja sebagai X2, dan Loan to Deposit Ratio (LDR) sebagai X3 berada diatas 0,10 yaitu 0,$983 ; 0,967 ; 0,966$ dan nilai variance inflation factor (VIF) angka berada dibawah 10 yaitu 1,017; 1,034; 1,035. Jadi dapat disimpulkan bahwa penelitian ini tidak terjadi multikolinearitas.

Uji Autokorelasi

Uji autokorelasi bertujuan untuk menguji apakah dalam suatu model regresi ada korelasi antara kesalahan pengganggu pada periode $t$ dengan kesalahan pada periode t-1 (sebelumnya). Jika terjadi autokorelasi maka dikatakan ada problem autokorelasi. Gejala autokorelasi menggunakan Durbin Watson (DW). Berikut adalah hasil uji autokorelasi dalam penelitian ini.

Tabel 3 Hasil Uji Autokorelasi

Model Summary

\begin{tabular}{|l|r|r|r|r|r|}
\hline Model & R & R Square & Adjusted R Square & Std. Error of the Estimate & Durbin-Watson \\
\hline 1 & $.599^{\mathrm{a}}$ & .359 & .343 & 3.66458 & 1.935 \\
\hline
\end{tabular}

a. Predictors: (Constant), SQRT_X3, SQRT_X1, SQRT_X2

b. Dependent Variable: SQRT_Y

Berdasarkan tabel diatas dapat disimpulkan bahwa hasil uji DW adalah 1,935 dengan $\mathrm{dl}=1,6513$ dan nilai $\mathrm{du}=1,7536$, maka syarat tidak ada korelasi negatif telah terpenuhi yaitu $d u<d<4-d u ; 1,7536<1,935<4-1,7536$; $1,7536<1,935<2,2464$. Maka dapat disimpulkan bahwa data tidak ada aukorelasi positif dan negatif.

Uji Heteroskedastisitas

Uji heteroskedastisitas bertujuan menguji apakah dalam model regresi terjadi ketidaksamaan variance dari residual satu pengamatan ke pengamatan yang lain. Model regresi yang baik adalah yang homoskedastisitas atau tidak mengalami gejala heteroskedastisitas.

Uji heteroskedastisitas lainnya dapat dilakukan dengan uji Glejser. Uji Glejser dengan nilai signifikan dari kedua variabel independen dengan nilai absolut $>0,05$ maka tidak terjadi heteroskedastisitas. Berikut hasil uji Glejser.

Tabel 3 Hasil Uji Glejser

Tabel 3 Hasil Uji Glejser

\begin{tabular}{|c|c|c|c|c|c|c|c|}
\hline \multirow[t]{2}{*}{ Model } & \multicolumn{2}{|c|}{$\begin{array}{l}\text { Unstandardized } \\
\text { Coefficients }\end{array}$} & $\begin{array}{l}\text { Standardized } \\
\text { Coefficients }\end{array}$ & \multirow[t]{2}{*}{$T$} & \multirow[t]{2}{*}{ Sig. } & \multicolumn{2}{|l|}{$\begin{array}{l}\text { Collinearity } \\
\text { Statistics }\end{array}$} \\
\hline & $\mathrm{B}$ & Std. Error & Beta & & & Tolerance & VIF \\
\hline (Constant) & 3.666 & 1.451 & & $\begin{array}{l}2.52 \\
7\end{array}$ & .013 & & \\
\hline SQRT_X1 & -.048 & .053 & -.083 & -.904 & 368 & .983 & 1.017 \\
\hline SQRT_X2 & 1.448E-007 & .000 & .173 & $\begin{array}{l}1.86 \\
2\end{array}$ & .065 & .967 & 1.034 \\
\hline
\end{tabular}


\begin{tabular}{lllll|l|l|l} 
[SQRT_X3 & -.002 & 1.008 & -.026 & -.285 & .776 & .966 & 1.035 \\
\hline
\end{tabular}

a. Dependent Variable: ABS_RES1

Dari hasil uji Glejser pada tabel diatas menunjukkan nilai signifikan inflasi sebesar 0,368 lebih besar dari 0,05, nilai signifikan modal kerja 0,065 lebih besar dari 0,05 begitu pula dengan Loan to Deposit Ratio (LDR) 0,776 lebih besar dari 0,05, jadi dari hasil uji glejser dapat diketahui bahwa inflasi, modal kerja, dan LDR tidak mengalami heteroskedastisitas.

Koefisien Determinasi (R2)

Koefisien determinasi berfungsi untuk melihat sejauh mana keseluruhan variabel independen dapat menjelaskan variabel dependen. Apabila R2 sama dengan 0, maka variasi independen yang digunakan dalam model tidak menjelaskan sedikitpun variasi variabel independen. Jika R2 semakin besar mendekati 1, maka dikatakan kemampuan variabel independen yang digunakan dalam model menjelaskan variabel dependen cukup besar.

Tabel 4 Koefisien Determinasi

Tabel 4 Koefisien Determinasi

\begin{tabular}{|l|l|l|l|l|l|}
\hline Model & $R$ & R Square & Adjusted R Square & Std. Error of the Estimate & Durbin-Watson \\
\hline 1 & $.599^{\mathrm{a}}$ & .359 & .343 & 3.66458 & 1.935 \\
\hline
\end{tabular}

a. Predictors: (Constant), SQRT_X3, SQRT_X1, SQRT_X2

b. Dependent Variable: SQRT_Y

Dari tabel diatas dapat diketahui bahwa nilai $R$ square diperoleh 0,359 atau 35,9\%. Hal ini berarti 35,9\% Return On Asset dapat dijelaskan oleh variasi dari ketiga variabel independen, yaitu inflasi, modal kerja dan Loan to Deposit Ratio. Sedangkan $64,1 \%$ dijelaskan oleh faktor-faktor lain yang tidak diteliti.

Pengujian Hipotesis Secara Simultan (Uji F)

Untuk membuktikan kebenaran dari suatu hipotesis, digunakan uji $F$ yaitu uji untuk mengetahui pengaruh variabel-variabel independen (inflasi, modal kerja, dan Loan to Deposit Ratio) secara simultan berpengaruh terhadap variabel dependen (Return On Asset).

Tabel 5 ANOVA

Tabel 5 ANOVA ${ }^{a}$

\begin{tabular}{|ll|l|l|l|l|l|}
\hline Model & & Sum of Squares & Df & Mean Square & F & Sig. \\
\hline \multirow{4}{*}{1} & Regression & 873.514 & 3 & 291.171 & 21.682 & $.000^{\circ}$ \\
& Residual & 1557.777 & 116 & 13.429 & & \\
& Total & 2431.291 & 119 & & & \\
\hline
\end{tabular}

a. Dependent Variable: SQRT_Y

b. Predictors: (Constant), SQRT_X3, SQRT_X1, SQRT_X2

Dari tabel diatas dapat diketahui nilai Fhitung sebesar 21,682 dan nilai Ftabel sebesar 2,66, maka Fhitung > Ftabel $(21,682>2,68)$. Nilai signifikan 0,000 lebih kecil dari 0,05, maka inflasi, modal kerja, dan Loan 
to Deposit Ratio berpengaruh signifikan terhadap Return On Asset pada perusahaan perbankan yang Terdaftar di BEI periode 2015-2019.

Pengujian Hipotesis Secara Parsial (Uji t)

Untuk membuktikan kebenaran suatu hipotesis, digunakan uji $\mathrm{t}$ yaitu uji untuk mengetahui apakah variabel-variabel independen berpengaruh secara parsial terhadap variabel dependen.

Table 6 Uji t

\section{Coefficients $^{\mathrm{a}}$}

\begin{tabular}{|c|c|c|c|c|c|c|c|}
\hline \multirow[t]{2}{*}{ Model } & \multicolumn{2}{|c|}{$\begin{array}{l}\text { Unstandardized } \\
\text { Coefficients }\end{array}$} & \multirow{2}{*}{\begin{tabular}{|l|}
$\begin{array}{l}\text { Standardized } \\
\text { Coefficients }\end{array}$ \\
Beta
\end{tabular}} & \multirow[t]{2}{*}{ T } & \multirow[t]{2}{*}{ Sig. } & \multicolumn{2}{|l|}{$\begin{array}{l}\text { Collinearity } \\
\text { Statistics }\end{array}$} \\
\hline & $B$ & Std. Erro & & & & Tolerance & VIF \\
\hline (Constant) & 7.440 & 2.281 & & 3.262 & .001 & & \\
\hline SQRT_X1 & -.158 & .084 & -.141 & 1886 & .062 & .983 & 1.017 \\
\hline SQRT_X2 & $\begin{array}{l}2.978 \mathrm{E}- \\
007\end{array}$ & .000 & .184 & 2.436 & .016 & .967 & 1.034 \\
\hline SQRT X3 & .103 & .013 & .599 & 7.917 & .000 & .966 & 1.035 \\
\hline
\end{tabular}

a. Dependent Variable: SQRT_Y

Berdasarkan tabel diatas dapat dijelaskan hasil pengujian secara parsial:

1. Pengujian hipotesis secara parsial (Uji t) untuk inflasi terhadap return on asset nilai thitung adalah $-1,886$ sedangkan ttabel sebesar 1,65381, maka -thitung <-ttabel $(-1,886<-1,65381)$ dan nilai signifikan 0,062 lebih besar dari 0,05 maka inflasi berpengaruh terhadap return on asset pada perusahaan perbankan yang terdaftar di BEl periode 2015-2019.

2. Pengujian hipotesis secara parsial (Uji t) untuk modal kerja terhadap return on asset nilai thitung adalah 2,436 sedangkan ttabel sebesar 1,65381 , maka thitung $>$ ttabel $(2,436>1,65381)$ dan nilai signifikan 0,016 lebih kecil dari 0,05 maka modal kerja berpengaruh signifikan terhadap return on asset pada perusahaan perbankan yang terdaftar di BEl periode 2015-2019.

3. Pengujian hipotesis secara parsial (Uji t) untuk loan to deposit ratio terhadap return on asset nilai thitung adalah 7,917 sedangkan ttabel sebesar 1,65381, maka thitung $>$ ttabel $(7,917>1,65381)$ dan nilai signifikan 0,000 lebih kecil dari 0,05 maka loan to deposit ratio berpengaruh signifikan terhadap return on asset pada perusahaan perbankan yang terdaftar di BEI periode 2015-2019.

\section{PEMBAHASAN}

Pengaruh inflasi Terhadap Return On Asset

Berdasarkan hasil uji hipotesis secara parsial (uji t) diperoleh hasil bahwa inflasi berpengaruh terhadap Return On Asset pada perusahaan perbankan yang terdaftar di BEl periode 2015-2019 dengan -thitung <ttabel $(-1,886<-1,65381)$ dan nilai signifikan 0,062 lebih besar dari 0,05 
Menurut (Fahmi, 2012, hal. 80), inflasi dapat menaikkan pendapatan dan biaya bagi perusahaan, yaitu jika kenaikkan biaya produksi lebih tinggi dari peningkatan harga yang dapat dinikmati oleh perusahaan maka profitabilitas akan turun.

Hasil penelitian ini menunjukan adanya hubungan negatif antara inflasi terhadap profitabilitas. Hal ini disebabkan oleh karena tingkat inflasi yang meningkat mengakibatkan kebijakan dalam kenaikan suku bunga (Sanusi, 2014).

Pengaruh modal kerja Terhadap Return On Asset

Berdasarkan hasil uji hipotesis secara parsial (uji t) diperoleh hasil bahwa modal kerja berpengaruh signifikan terhadap Return On Asset pada perusahaan perbankan yang terdaftar di BEI periode 2015-2019 dengan nilai thitung $>$ ttabel $(2,436>1,65381)$ dan nilai signifikan 0,016 lebih besar dari 0,05.

Menurut (Sudana, 2011, hal. 197), perusahaan yang menerapkan kebijakan investasi modal kerja agresif cenderung mempertahankan jumlah modal kerja yang relatif kecil untuk tingkat penjualan tertentu. Kebijakan modal kerja agresif memiliki implikasi tingkat likuiditas perusahaan yang rendah, namun disisi yang lain profitabilitas perusahaan tinggi, karena jumlah aktiva lancarnya kecil (Ghozali, 2013).

Hasil penelitian menunjukan bahwa ada hubungan positif antara modal kerja terhadap profitabilitas dimana ini menunjukan adanya pemanfaatan modal kerja yang baik akan meningkatkan profitabilitas perusahaaan.

Pengaruh Loan to Deposit Ratio Terhadap Return On Asset

Berdasarkan hasil uji hipotesis secara parsial (uji t) diperoleh hasil bahwa

Loan to Deposit Ratio berpengaruh signifikan terhadap Return On Asset pada perusahaan perbankan yang terdaftar di BEl periode 2015-2019 dengan -thitung $<$-ttabel $(-7,917<-1,65381)$ atau thitung $>$ ttabel $(7,917>$ 1,65381 ) dan nilai signifikan 0,000 lebih kecil dari 0,05 .

Menurut (Hariyani, 2010, hal. 57), menyatakan besarnya LDR akan berpengaruh terhadap laba melalui penciptaan kredit. LDR yang tinggi mengindikasikan adanya penanaman dana dari pihak ketiga yang besar ke dalam bentuk kredit. Kredit yang besar akan meningkatkan laba.

Kesimpulan adalah:

Berdasarkan penelitian ini, maka kesimpulan yang dapat diambil 1. Inflasi berpengaruh tidak signifikan terhadap Return On Asset pada perusahaan perbankan yang terdaftar di BEI periode 2015-2019.

2. Modal kerja berpengaruh signifikan terhadap Return On Asset pada perusahaan perbankan yang terdaftar di BEI periode 2015-2019.

3. Loan to Deposit Ratio berpengaruh signifikan terhadap Return On Asset pada perusahaan perbankan yang terdaftar di BEI periode 20152019. 
4. Inflasi, modal kerja, dan Loan to Deposit Ratio berpengaruh signifikan terhadap Return On Asset pada perusahaan perbankan yang Terdaftar di BEI periode 2010-2014. Koefisien determinasi yang dihasilkan sebesar $34,3 \%$ yang artinya variasi dari ketiga variabel independen, yaitu inflasi, modal kerja, dan Loan to Deposit Ratio berhasil menjelaskan $34,3 \%$ variabel dependen yaitu Return On Asset. Sedangkan sisanya $65,7 \%$ dijelaskan oleh variabel independen lain diluar penelitian ini.

\section{DAFTAR PUSTAKA}

Alpi, M. F. (2018). Pengaruh Debt to Equity Ratio, Inventory Turn Over, dan Current Ratio terhadap Return on Equity pada Perusahaan Sektor Farmasi yang Terdaftar di Bursa Efek Indonesia. The National Conference on Management and Business (NCMAB) (hal. 158). Surakarta: Program Studi Manajemen, Fakultas Ekonomi dan Bisnis Kampus II UMS.

Fahmi, I. (2012). Analisis Kinerja Keuangan. Bandung: CV. Alfabeta.

Fahmi, I. (2012). Pengantar Manajemen Keuangan. Bandung: CV. Alfabeta.

Fahmi, I. (2013). Manajemen Investasi. Jakarta Selatan: Salemba Empat.

Fitriani Saragih, P. K. (2017). EFFECT OF PROFITABILITY, LIQUIDITY AND QUALITY OF AUDITORS AUDIT OPINION GOING CONCERN IN FOOD AND DRINK LISTED IN INDONESIA STOCK EXCHANGE (IDX). Proceeding 3rd Sriwijaya Economics (hal. 208-222). Palembang: Accounting, and Business Conference 2017.

Ghozali, I. (2013). Aplikasi Analisis Multivariate dengan Program IBM. Jakarta: Universitas Diponegoro.

Harahap, S. S. (2008). Analisis Kristis Atas Laporan Keuangan. Jakarta: PT.Rajagrindo Persada.

Hariyani, I. (2010). Restrukturisasi dan Penghapusan Kredit Macet. Jakarta: PT.Elex Media Komputindo Kompas Gramedia.

Harmono. (2015). Manajemen Keuangan. Jakarta: Bumi Aksara.

Hery. (2015). Analisis Laporan Keuangan Pendekatan Rasio Keuangan. Yogyakarta: CAPS.

Husnan, S. \&. (2015). Dasar-Dasar Manajemen Keuangan. Yogyakarta: Unit Penerbit dan Percetakan.

Jumingan. (2014). Analisis Laporan Keuangan. Jakarta: Bumi Aksara.

Kasmir. (2012). Manajemen Perbankan. Jakarta: Rajagrafindo Persada.

Kuncoro, M. (2009). Metode Riset Untuk Bisnis dan Ekonomi. Jakarta: Erlangga.

Margaretha, F. (2007). Manajemen Keuangan Bagi Industri Jasa. Jakarta: Grasindo.

Murhadi, W. R. (2013). Analisis Laporan Keuangan. Jakarta: Salemba Empat.

Murhadi, W. R. (2013). Analisis Laporan Keuangan. Jakarta: Salemba Empat. 
Nainggolan, E. P. (2016). Pengaruh current ratio, debt to asset ratio, working capital turn over, total asset turn over terhadap return on asset pada perusahaan sektor pertambangan yang terdaftar di BEI. Kumpulan Jurnal Dosen Universitas Muhammadiyah Sumatera Utara, 576-590.

Pandia, F. (2012). Manajemen Dana dan Kesehatan Bank. Jakarta: Pt. Rineka Cipta.

Prasetyo, B. \&. (2010). Metode Penelitian Kuantitatif. Jakarta: Rajawali Pers.

Putong, I. (2008). Economics Pengantar Mikro dan Makro. Jakarta: Mitra Wacana Media.

Rahardja, P. \&. (2008). Pengantar IImu Ekonomi. Jakarta: Fakultas Ekonomi Universitas Indonesia.

Rajaharputra, H. S. (2011). Manajemen Keuangan dan Akuntansi. Jakarta Selatan: Salemba Empat.

Rialdy, N. (2019). Influence of Return on Equity (ROE), The Price Influence of Return on Equity (ROE), The Price Earnings Ratio (PER) and the Capital Structure of The Company's Share Price Against the Sub Sectors of Transport Registered in Bursaefek Indonesia (BEI) the Peri. International Journal of Accounting \& Finance in Asia Pasific (IJAFAP), 46-53.

Rosyidi, S. (2012). Pengantar Teori Ekonomi. Jakarta: PT.Rajagrindo Persada.

Sanusi, A. (2014). Metodologi Penelitian Bisnis. Jakarta: Salemba Empat.

Sembiring, M. (2019). ANALISIS RASIO LIKUIDITAS, PROFITABILITAS, SOLVABILITAS DAN PERPUTARAN PERSEDIAAN UNTUK MENILAI KINERJA PERUSAHAAN RETAIL YANG TERDAFTAR DI BEI. JURNAL AKUNTANSI BARELANG, 75-85.

Subramanyam, K. \&. (2013). Analisis Laporan Keuangan. Jakarta Selatan: Salemba Empat.

Sudana, I. M. (2011). Manajemen Keuangan Perusahaan. Jakarta: Erlangga.

Sujarweni, V. (2014). Metodologi Penelitian. Yogyakarta: Pustaka Baru Press.

Surya Sanjaya, R. P. (2019). Pengaruh Current Ratio, Debt to Asset Ratio dan Total Asset Turnover terhadap Return on Asset pada Perusahaan Otomotif dan Komponennya yang Terdaftar di Bursa Efek Indonesia. Jurnal Riset Akuntansi dan Bisnis, 136-150.

Suryabrata, S. (2012). Metodologi Penelitian. Jakarta: Rajawali Pers.

Wijaya, D. (2009). Manajemen Perbankan. Jakarta: Ghalia Indonesia. 